\title{
Art Characteristics and Teaching of Grace Note in Chinese Instrument Piano Paraphrase
}

\author{
Jing Guo \\ Ningxia Preschool Education College, Yinchuan, 750001, China
}

Keywords: Chinese instrument; Piano paraphrase; Grace note; Teaching method

\begin{abstract}
In recent years, China's piano music creation gains further development. Grace note becomes one of main expression languages of piano music style. To further know application features of grace note in piano paraphrase, this paper first sets forth application form of grace note in piano paraphrase and then deeply analyzes its art features. On this basis, this paper analyzes grace note teaching features in piano paraphrase so as to provide reference for teachers.
\end{abstract}

\section{Introduction}

From the perspective of development history, piano has 100-year development history in China, but its development momentum in Chinese music circle cannot be ignored. There are numerous Chinese traditional national instruments, and there are also many excellent national instrument works. As the introduction of piano, many throw themselves into researches on traditional instrumental music re-composition. A large number of excellent piano paraphrase works widely spread. Grace note as an important constituent part of piano paraphrase directly decides paraphrase quality and appreciation value. So, it is necessary to analyze application of grace note in Chinese instrument paraphrase and its art features, and propose suggestions on grace note teaching so as to expect cultivation of more piano talents.

\section{Application of grace note in Chinese piano paraphrase}

According to the types of grace notes, grace notes in Chinese piano paraphrase may be classified into appoggiatura, trill, and arpeggio chord.

\section{Appoggiatura}

With a general survey of Chinese piano paraphrase, we can find that expression patterns of appoggiatura are diversified. Its expression patterns and forms have obvious differences in different paraphrases. The application of appoggiatura adds unique natural and national characteristics of traditional Chinese instrument. For example, in Birds Paying Homage to The Phoenix, the paraphrase author creatively utilized minor second appoggiatura to simulate twitter so that sound in nature is fully reflected in piano paraphrases. In another successful piano paraphrase Yang Guan San Sie, large quantities of repeated appoggiatura appear so that melody after embellishment owns strong national features, and the mild and indirect feeling in music is reflected vividly.

Except individual use of appoggiatura, the adaptor creatively combines appoggiatura and other special rhythms. For instance, in the primer of Plum-blossom in Three Movements, the author applied octave appoggiatura in bass area to simulate discrete sound generated by Guqin (a Chinese instrument) in music score of traditional instrument. It well displays deep feeling of original music score. In Moon over the Peaceful Lake in Autumn, rear appoggiatura of octave was utilized to simulate ottava alta portamento. It well reflects national features contained in the music score.

\section{Arpeggio chord}

Embellishment of notes by arpeggio chord can express music situations at different levels. This feature is also fully reflected in Chinese instrument piano paraphrases. For instance, at the loud part of Moon over the Peaceful Lake in Autumn, almost each syllable is fully embellished by arpeggio chord. In Erhu music The Moon Over a Fountain, just individual syllables are embellished by 
arpeggio chord to help the audiences reflect sadness expressed in the music score and play the role in making the finishing point.

Trill

Trill is a common grace note form in Chinese piano paraphrases. In Birds Paying Homage to The Phoenix, the adaptor used continuous trill during simulating chirping of cicada in original music score. Thus, the expression force of music is enhanced significantly. In Moon over the Peaceful Lake in Autumn, the trill use mode is unique, i.e. use continuous and extending trill to simulate deep tone in traditional music score. This well creates quiet and beautiful situation and brings the audiences high-quality auditory sense experience.

\section{Art characteristics of grace note}

Grace note ha significant application effect in Chinese instrument piano paraphrases. Main expression forms of its art characteristics mainly include the following:

\section{Fully display temperament of national instrument}

Grace note can embellish on the basis of original melody so that the final performance effect is more graceful. Scientific and rational utilization of grace note to embellish national music is a key factor to make sure temperament of the whole national instrument is kept completely. Next, this paper uses case form to explain specific representation of temperament of national instrument.

For example, in the original version of Birds Paying Homage to The Phoenix, Suona (a woodwind instrument) was used. In piano paraphrase, the author well kept unique lingering charm of Suona performance. In this music score, grace note is used to simulate birdcall, cicada stridulation and ripple in original music. The whole music can still make the audiences feel traditional national features and lingering charm after re-composition of piano music. Meanwhile, grace note can not just gain good performance effects and optimize audiences' auditory sense experience in Chinese instrument piano paraphrases, but also effectively fuse Chinese and western music culture, effectively inherit and develop Chinese excellent national music while the advantages of piano are fully exerted.

\section{Better reflect beauty of artistic conception in Chinese instrumental music}

Reflecting a fusion of feelings with situations in music is the highest stage of music performance. This characteristic is also clearly reflected in Chinese instrument piano paraphrase. Chinese traditional music is characterized by "linear thinking". It is different from "three-dimensional thought" of western music including piano. This is a key influencing factor in Chinese instrument piano paraphrase. The use of grace note makes composers' melody treatment possible. Composers may treat instrumental music on the basis of wide range and abundant force of piano so as to perfectly combine transverse melody and lengthways chord. Nevertheless, the use of grace note is also beneficial to expressing unique "overtones” of Chinese traditional instrument. Take Music at Sunset Time for example. In primer music, appoggiatura, grace note and chord are used in the piano paraphrase to try to simulate the drum sound and the sound generated by river water flapping the bank. In this process, piano playing force is utilized to simulate original effect played by pipa. Then, grace note is used to simulate long $\mathrm{Li}$ tone in Guzheng melody. Finally, trill and arpeggio chord simulate wave sound generated by Xiao (a vertical bamboo flute). A beautiful situation where the setting sun shines and the wind blows over ripples on the surface of the river is shown in the face of audiences.

Another representative piano paraphrase is Plum-blossom in Three Movements. In primer music, octave, appoggiatura chord are used. The playing force enhances to achieve large-span range and mutually reflect with grace note to form "empty sound" phenomenon. Deep and distant situation is well shown. The grace note is used at the end to further enhance the theme of music and highlight beautiful situation of "wintersweet outshining others".

\section{Grace note teaching in Chinese piano paraphrase}

Compared with western piano education, China has a short history in this aspect and lacks representative piano works. Thus, in Chinese piano music teaching, western music works serve as the main teaching materials, such as Beethoven and Chopin. However, when students' skills reach certain degree, they will generally reach to Chinese music works more or less. Then, they may be 
easily influenced by western music performance thought and habits. Thus, traditional national characteristics in Chinese instrumental music cannot be fully reflected, and serious "distortion" phenomenon appears in re-composition or paying process. Since there is a wide range of Chinese traditional instruments, any piano music recomposed from traditional instrumental music, every type of grace note is different. In particular, when a grace note appears in multiple places in a song, the playing force and speed do not follow fixed mode. Players should fully know artistic conception and emotional expression of original music and be familiar with tone features of original musical instrument to better complete music creation. His also provide guidance for Chinese instrument piano paraphrase teaching.

\section{Guide students to master creation background and emotional expression of works}

Most Chinese traditional instruments develop and evolve after very long historical inheritance and own unique charm. Re-composition of Chinese instrumental music to piano music is of inheritance of Chinese traditional music culture. Hence, it is required to pay attention to playing skills in piano teaching and guiding students to deeply know and experience creation background and emotional expression of Chinese instrumental music. In this way, students can play the piano in combination of their art deposits after mastering piano paraphrase so as to reach a favorable playing effect. For instance, during organizing to learn Birds Paying Homage to The Phoenix, the following steps should be followed. Firstly, teachers should guide students to understand original music. Birds Paying Homage to The Phoenix was originally a Suona solo. It was recomposed to piano music by Wang Jianzhong in 1973. Appoggiatura, trill and arpeggio chord are applied in quantity in the recomposed music to vividly simulate Suona playing effects. The situation where hundreds of birds sing is perfectly presented. Secondly, teachers should guider students to listen to playing effects of original music, imagine and describe the artistic conception to help them overall comprehend emotional expression and art characteristics in the original works and cognize that the author expresses his deep love for nature through use of grace notes in quantity. Thirdly, students may play excellent voice frequency works through playing recomposed piano music, and compare it with original Suona version to more deeply know different performance features of the two so as to more proficiently play and express grace note in piano music score in piano playing process. Finally, teachers should guide students to play and guide them after their performance until they reach teaching requirements.

\section{Guide students to carefully appreciate beautiful artistic conception of works}

Chinese traditional instrumental music works attach importance to combination of artistic conception expression and situations. So, composers will usually utilize a large number of grace notes with Chinese characteristics during recomposing traditional music so that traditional music culture and characteristics in the original music more fully reflected. In the teaching process, teachers may provide explanations for students while guiding them to appreciate the music through playing paraphrases of different types. For instance, since the keynote of Music at Sunset Time is brisk, performers should keep quiet mind and body so as to more smoothly blend in the situation, make quiet and beautiful situation run through the whole performing process and bring audiences auditory sense feast. During teaching The Moon Over a Fountain, the teacher may introduce Rosy Clouds Chasing The Moon and Moon over the Peaceful Lake in Autumn for comparative teaching. Although the three depict the moon, there are significant differences in the situations. Main keynote of The Moon Over a Fountain is desolate, so chill is dominated during playing it. Rosy Clouds Chasing The Moon mainly expresses the feeling of pureness, so coherence and soft actions should be noticed during playing the grace note to keep the euphemistic style. The emotional keynote of Moon over the Peaceful Lake in Autumn is dominated by quietness and stability. During playing it, the teacher should guide students to keep peaceful mood so as to make the whole process successive.

\section{Attach importance to piano playing skill training}

In Chinese instrument piano paraphrase teaching process, except emphasizing and valuing the above skills, basic playing skill training for students cannot be ignored. Proficient mastery of playing skills is a basic guarantee to make sure piano music completed smoothly. So, it is required to pay attention to it. For instance, apart from playing practice, students may be organized to carry out experience exchange to help them cognize the skills. This is also beneficial to thought collision. In 
this process, teachers may take active part and summarize playing skills through teaching their own playing experience so as to improve students' playing level and help them understand emotional expression of grace notes in piano paraphrases in order to gain twofold results with the half effort.

\section{Conclusions}

In conclusion, Chinese instrument piano paraphrase is an important channel for Chinese and western music cultures to achieve good fusion. Meanwhile, it inherits and develops Chinese traditional music culture. In the playing process, it is required to be based on emotional expression and at characteristics of original music, proficiently master expression patterns of grace note in recomposed piano music and well reflect emotion of original music in the recomposed music. Meanwhile, during conducting relevant teaching activities, the above two should serve as key contents in teaching and adopt examples for teaching. Moreover, it is also required to pay attention to training students' basic playing skills so as to make them fully interpret recomposed piano music. On in this way, a solid foundation can be laid for inheritance of Chinese music culture to better inherit and develop Chinese traditional music culture.

\section{References}

[1] Ren Yuan, Art characteristics and teaching of grace notes in Chinese instrument piano paraphrase. Hundred Schools in Arts, 2011, S2:393-395

[2] Li Yi, Art characteristics of recomposed piano music from traditional music based on The Moon Over a Fountain and Birds Paying Homage to The Phoenix. Northeast Normal University, 2011

[3] Mou Jingjing, Study on Chinese piano paraphrase at the beginning of founding the state. Shandong Normal University, 2014

[4] Fang Ou, Study on piano paraphrase of Chinese national music. Fujian Normal University, 2014

[5] Ding Feifei, Art characteristics of recomposed piano music Four Folk Songs of North Shaanxi. Journal of Xinjiang Arts University, 2010, 01:45-48.

[6] Yang Lili, Study on national features of Wang Jianzhong's Chinese piano paraphrase. Journal of Changzhou Institute of Technology (Social Science Edition), 2010, 03:52-57

[7] Liu Min, traditional stringed and woodwind instruments of grace note in Chinese piano paraphrase. Yihai, 2014,10:79-81

[8] Dong Xiaomei, Exploration of nationalization creation method in Wang Jianzhong's piano paraphrase Birds Paying Homage to The Phoenix. Music Creation, 2012,12:123-125

[9] Xia Chang, Study on creative characteristics of Chinese piano paraphrase. Art Education, 2015,01:136-137 